IJPSR (2011), Vol. 2, Issue 2

(Research Article)

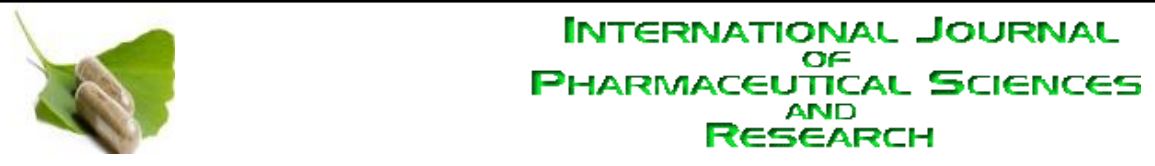

Received on 11 September, 2010; received in revised form 12 November, 2010; accepted 14 January, 2011

\title{
DEVELOPMENT AND EVALUATION OF SUSTAINED RELEASE MATRIX TABLET OF LAMIVUDINE
}

Swati Jain*, Neelesh Kumar Mehra, Akhlesh Kumar Singhai and Gaurav Kant Saraogi

Department of Pharmaceutics, Lakshmi Narayan College of Pharmacy, Bhopal, Madhya Pradesh, India

Keywords:
Controlled release,
Guar gum,
Lamivudine,
Matrix tablets

Correspondence to Author:

Swati Jain

Department of Pharmaceutics, Lakshmi Narayan College of Pharmacy, Bhopal, Madhya Pradesh, India

\begin{abstract}
The study was obtained to develop oral controlled release matrix tablets of Lamivudine having different proportion of Guar gum (retardant polymer) and to study the effect of formulation factor such as polymer proportion on the in-vitro release. The prepared granules were evaluated such as angle of repose, loose bulk density, tapped bulk density and compressibility index and satisfactory results were obtained. Compressed tablets were also evaluated for uniformity of weight, content of active ingredient, thickness, friability, hardness, swelling, erosion behaviour and in-vitro dissolution studies. All the formulations showed good results which were compliance with Pharmacopoeial standards. In-vitro drug release studies were carried out using USP XXII dissolution apparatus type II at 50 rpm with $900 \mathrm{ml}$ phosphate buffer solutions (PBS) of $\mathrm{pH} \mathrm{6.8,}$ maintained at $37 \pm 0.5^{\circ} \mathrm{C}$. The release kinetics was analyzed using the zero-order, first-order model equation, Higuchi's squareroot equation, and the Korsmeyer-peppas model. In vitro release studies revealed that the release rate decreased with increases in polymer proportion. Matrix tablets containing $15 \%$ guar gum (Formulation F2) were found to show good initial release (21.34\% in initial hour) and allowed sustained release up to 12 hours. Mathematical analysis of the release kinetics indicated that the nature of drug release from the matrix tablets was dependent on polymer concentration and it was found to be diffusion coupled with erosion. The developed controlled release matrix tablets of lamivudine, with sustained release characteristics might be able to minimise the demerits of conventional therapy having lamivudine.
\end{abstract}

Available online on www.ijpsr.com

454 
INTRODUCTION: The oral route is the most common route used for administration of drugs. Tablets are the most popular oral solid formulations available in the market and are preferred by patients and physicians alike. In longterm therapy for the treatment of chronic disease conditions, conventional formulations are required to be administered in multiple doses and therefore have several disadvantages ${ }^{1}$. Controlled release (CR) tablet formulations are preferred for such therapy because they offer better patient compliance, maintain uniform drug levels, reduce dose and side effects, and increase the safety margin for high-potency drugs ${ }^{2}$.

Acquired immune deficiency syndrome (AIDS) is considered to be an epidemic, and according to estimates from the Joint United Nations Programme on HIV/AIDS (UNAIDS) and the World Health Organization (WHO) AIDS Epidemic Update 2005, 38 million adults and 2.3 million children were living with the human immunodeficiency virus (HIV) at the end of 2005. The annual number of AIDS deaths can be expected to increase for many years to come, unless more effective and patient-compliant anti-retroviral medications are available at affordable prices ${ }^{3}$. The major drawbacks of antiretroviral drugs for the treatment of AIDS are their adverse side effects during long-term therapy, poor patient compliance, and their huge cost ${ }^{4-5}$. Lamivudine (LAM) is a potent antiviral agent used in the treatment of AIDS. Conventional oral formulations of LAM are administered multiple times a day $(150 \mathrm{mg}$ twice daily) because of its moderate half-life $\left(t_{1 / 2}=5-7\right.$ hours) ${ }^{6-8}$.

Development of oral controlled release matrix tablets for water-soluble drugs with constant release rate has always been a challenge to the pharmaceutical technologist. Most of the drugs, if not formulated properly, may readily release the drug at a faster rate and produce a toxic concentration of the drug on oral administration. In recent years, considerable attention has been focused on hydrophilic polymers in the design of oral controlled drug delivery systems because of their flexibility to obtain a desirable drug release profile, costeffectiveness, and broad regulatory acceptance. Among the hydrophilic polymers, cellulose derivatives such as methyl cellulose (MC), Hydroxypropyl Methylcellulose (HPMC), and Sodium carboxymethyl cellulose ( $\mathrm{NaCMC}$ ), are generally considered to be stable and safe as release retardant excipients in the development of oral controlled release dosage forms. These semi synthetic polymers are quite expensive when compared with natural polymers such as guar gum, alginates, and so forth. The natural polymers are non-toxic and easily available.

The objective of the present investigation was to develop oral controlled release tablets for water soluble Lamivudine using a natural polymer such as guar gum. Guar gum is a non-ionic polysaccharide derived from the seeds of Cyamopsis tetragonolobus, family Leguminosae. It consists of linear chains of (1-4)- $\beta-D$ mannopyranosyl units with $\alpha$-D-galactopyranosyl units attached by (1-6) linkages. In pharmaceuticals, guar gum is used in solid dosage forms as a binder and disintegrant ${ }^{9-11}$. A few reports appear on the use of guar gum, as a hydrophilic matrix, for designing oral controlled release dosage forms ${ }^{9,12-13}$. The efficiency of the hydrophilic matrix in controlling the drug release, in addition to other factors, is dependent on the viscosity of the hydrophilic polymer(s) incorporated in the formulation ${ }^{14-15}$. Hence, in the present study Matrix tablets containing six different proportions of various viscosity grades of guar gum were prepared by wet granulation method and subjected to in vitro drug release studies to find the utility of guar gum in providing controlled release. 
MATERIALS AND METHODS: Lamivudine was obtained as a gift sample from (Strides Arcolab, Bangalore), Guar gum from S.D. Fine Chemicals, Mumbai. HPMC K100M from Dr Reddy's Lab (Hyderabad, India), Micro Crystalline Cellulose and Magnesium stearate from Loba Chem (Mumbai, India). All other chemicals and ingredients were used for study are of analytical grade.

\section{Preparation of Lamivudine Hydrochloride Matrix} Tablets: Matrix tablets of Lamivudine Hydrochloride were prepared by wet granulation method. The composition of various formulations is given in Table 1. Lamivudine, Guar gum and Avicel (pH 10) were mixed in a poly-bag, and the mixture was passed through mesh (No.60). Granulation was done using a solution of PVP (K-30) in sufficient isopropyl alcohol. Then pass though mesh No. 16, and the wet granules were air dried for 2 hours.

The prepared granules were then sized by mesh No. 22 and then mixed with Magnesium stearate and Talc. Tablets were compressed using Rotary tablet machine with $10 \mathrm{~mm}$ standard concave punch. Tablet weight was (400mg) kept constant as shown in Table 1 . Six different formulas, having different concentrations of guar gum $(10 \%, 15 \%, 20 \%, 25 \%, 30 \%$ and $40 \%)$, were developed and evaluate the various evaluator parameters with drug release and to study the effect of polymer concentration on drug release.

TABLE 1: COMPOSITION OF VARIOUS FORMULATIONS

\begin{tabular}{ccccccc}
\hline Ingredient & F1 & F2 & F3 & F4 & F5 & F6 \\
\hline Lamivudine & 200 & 200 & 200 & 200 & 200 & 200 \\
Guar gum & 40 & 60 & 80 & 100 & 120 & 160 \\
$\begin{array}{c}\text { PVP K-30 } \\
\text { Avicel }\end{array}$ & 20 & 20 & 20 & 20 & 20 & 20 \\
pH (10) & 128 & 108 & 88 & 68 & 48 & 08 \\
$\begin{array}{c}\text { Magnesium } \\
\text { stearate }\end{array}$ & 08 & 08 & 08 & 08 & 08 & 08 \\
Talc & 04 & 04 & 04 & 04 & 04 & 04 \\
\hline
\end{tabular}

Evaluation of Prepared Granules ${ }^{16-18}$ : The physical properties of granules were shown in Table 2.

1. The angle of repose of prepared granules was determined by using fixed funnel method, which indicates the flow-ability of the granules.

Angle of Repose $(\theta)=\operatorname{Tan}^{-1}$ (Height of pile/Radius of the base of the pile)

2. Loose bulk density (LBD) and tapped bulk density (TBD) [17] were measured using the formula:

$\mathrm{LBD}=$ weight of the powder / volume of the packing

$\mathrm{TBD}=$ weight of the powder / tapped volume of the packing

3. Compressibility index $(\mathrm{Cl})$ of the granules was determined by using the formula:

$$
\mathrm{Cl}(\%)=[(\mathrm{TBD}-\mathrm{LBD} / \mathrm{TBD})] \times 100
$$

Evaluation of Tablets: All prepared matrix tablets were evaluated for its uniformity of weight, hardness, friability and weight variation test, thickness according to official methods ${ }^{19}$. Results are shown in Table 3.

Thickness: Thickness of tablets was determined by using screw gauze. The thickness of 10 tablets was determined randomly in $\mathrm{mm}$.

Hardness: The hardness of tablets determined by using Monsanto hardness tester (MHT-20, Campbell Electronics, Mumbai, India. The tablet was held between affixed and moving jaw. Scale was adjusted to zero; load wad gradually increased until the tablet fractured. The value of the load at that point gave a measure of the hardness was expressed in $\mathrm{Kg} / \mathrm{cm}^{2}$. 
Friability: Friability was determined using Roche friabilator (FTA-20, Campbell Electronics). 20 tablets were weighed and placed in the friabilator and then operated at 25 RPM for 4 minutes. The tablets were then de-dusted and weighed. The \% friability was calculated using this formula:

$$
\text { Friability }=100 \times\left(1-\mathrm{W}_{1} / \mathrm{W}_{2}\right)
$$

Where, $\mathrm{W}_{1}$ : Initial weight before friabilator,

$$
\mathrm{W}_{2} \text { : Final weight after friabilator }
$$

Drug Content: Five tablets were powdered in a mortar. An accurately weighed quantity of TABLE 2: TABLET PROPERTIES OF THE DIFFERENT FORMULATIONS OF LAMIVUDINE CONTROLLED RELEASE MATRIX TABLETS

\begin{tabular}{ccccccc}
\hline PARAMETERS & \multicolumn{5}{c}{ Formulation Code } \\
\cline { 2 - 7 } & F1 & F2 & F3 & F4 & F5 \\
\hline Angle of repose & $25.32 \pm 1.45$ & $28.71 \pm 1.46$ & $25.24 \pm 1.25$ & $27.07 \pm 1.31$ & $29.49 \pm 1.28$ & $27.64 \pm 1.23$ \\
Loose Bulk Density $(\mathrm{g} / \mathrm{ml})$ & $0.3354 \pm 0.01$ & $0.3604 \pm 0.03$ & $0.3454 \pm 0.05$ & $0.3643 \pm 0.06$ & $0.4153 \pm 0.04$ & $0.3942 \pm 0.06$ \\
Tapped bulk Density $(\mathrm{g} / \mathrm{ml})$ & $0.4532 \pm 0.008$ & $0.4261 \pm 0.002$ & $0.4956 \pm 0.003$ & $0.3979 \pm 0.004$ & $0.4496 \pm 0.006$ & $0.5054 \pm 0.008$ \\
Compressibility index $(\%)$ & $14.16 \pm 0.26$ & $12.53 \pm 0.25$ & $13.25 \pm 0.36$ & $16.50 \pm 0.21$ & $11.42 \pm 0.43$ & $16.72 \pm 0.38$ \\
\hline
\end{tabular}

TABLE 3: GRANULE PROPERTIES OF THE DIFFERENT FORMULATIONS OF LAMIVUDINE CONTROLLED RELEASE MATRIX TABLETS

\begin{tabular}{ccccccc}
\hline \multirow{2}{*}{ PARAMETERS } & \multicolumn{5}{c}{ Formulation Code } \\
\cline { 2 - 7 } & F1 & F2 & F3 & F4 & F5 & F6 \\
\hline Thickness $(\mathbf{m m})$ & $3.75 \pm 0.04$ & $3.83 \pm 0.05$ & $3.76 \pm 0.01$ & $3.92 \pm 0.07$ & $3.78 \pm 0.02$ & $3.87 \pm 0.06$ \\
Hardness $\left(\mathbf{k g} / \mathbf{c m}^{2}\right)$ & $6.2 \pm 0.12$ & $6.6 \pm 0.28$ & $6.4 \pm 0.45$ & $6.5 \pm 0.39$ & $6.3 \pm 0.04$ & $6.8 \pm 0.14$ \\
Friability (\%) & 0.29 & 0.31 & 0.33 & 0.39 & 0.42 & 0.32 \\
Drug content (\%) & $97.82 \pm 0.41$ & $99.11 \pm 0.16$ & $98.16 \pm 0.47$ & $98.62 \pm 0.35$ & $97.68 \pm 0.18$ & $99.12 \pm 0.18$ \\
\hline
\end{tabular}

The values represent mean \pm S.D; $n=3$

In-vitro Drug Release Studies: In-vitro drug release studies were carried out using USP XXII dissolution apparatus type II (Electrolab, Mumbai, India) at 50 rpm. The dissolution medium consisted of $900 \mathrm{ml}$ of $\mathrm{pH} 6.8$ phosphate buffer, maintained at $37 \pm 0.5^{0} \mathrm{c}$. The drug release at different time intervals was measured using an ultraviolet visible spectrophotometer (Labindia, Mumbai, India) at $266 \mathrm{~nm}$. The study was performed in triplicate. powdered tablets (100 $\mathrm{mg}$ ) was extracted with $\mathrm{pH}$ 6.8 buffer and the solution was filtered through $0.45 \mu$ membranes. The absorbance was measured at $266 \mathrm{~nm}$ after suitable dilution.

Weight Variation Test: 20 tablets were weighed individually and average weight was calculated (type ER182A, Afcoset, Mumbai, India). The individual weighs were then compared with average weight. The tablet passes the test if not more than 2 tablets fall outside the \% limit and none of tablet differs by more than double $\%$ limit. 
Drug Release Kinetics: To study the release kinetics, data obtained from in vitro drug release studies were plotted in various kinetic models: zero order (Equation 1) as cumulative amount of drug release vs time, first order (Equation 2) as log cumulative percentage of drug remaining vs time, and Higuchi's model (Equation 3) as cumulative percentage of drug released vs square root of time (table 4).

$$
\mathrm{C}=\mathrm{K}_{0} \mathrm{t}
$$

Where $K_{0}$ is the zero order rate constant expressed in units of concentration / time and $t$ is the time in hours. A graph of concentration vs time would yield a straight line with a slope equal to $K_{0}$ and intercept the origin of the axes ${ }^{20}$.

$$
\log C=\log C_{0}-K t / 2.303
$$

Where $C_{0}$ is the initial concentration of drug, $k$ is the first order constant, and $t$ is the time ${ }^{21}$.

$$
\mathrm{Q}=\mathrm{kt}^{\mathrm{t}} \mathrm{1} / 2
$$

Where $K$ is the constant reflecting the design variables of the system and $t$ is the time in hours. Hence, drug release rate is proportional to the reciprocal of the square root of time ${ }^{22}$.

Mechanism of Drug Release: To evaluate the mechanism of drug release from zidovudine controlled release tablets, data of drug release were plotted in korsmeyer et al's equation (Equation 4) as log cumulative percentage of drug release vs log time and the exponent $n$ was calculated through the slope of the straight line.

$$
\mathrm{Mt} / \mathrm{M} \infty=\mathrm{kt} \mathrm{t}^{\mathrm{n}}
$$

Where $M t / M \infty$ is the fractional solute release, $t$ is the release time, $K$ is a kinetic constant characteristics of the drug/polymer system, and $n$ is an exponent that characterizes the mechanism of release of tracers ${ }^{23}$. For cylindrical matrix tablets, if the exponent $n=0.45$, then the drug release mechanism is Fickian diffusion, and if $0.45<n$ $<0.89$, then it is non-Fickian or anomalous diffusion. An exponent's value of 0.89 is indicative of case-II Transport or typical zero-order release ${ }^{24}$.

TABLE 4: RELEASE KINETICS PARAMETERS OF DESIGNED CONTROLLED RELEASE MATRIX TABLETS OF LAMIVUDINE

\begin{tabular}{cccccc}
\hline \multirow{2}{*}{ Formulations } & Zero order & First order & \multicolumn{2}{c}{ Higuchi's } & \multicolumn{2}{c}{ Korsmeyer et al., plots } \\
\cline { 2 - 6 } & $\mathbf{R}^{\mathbf{2}}$ & $\mathbf{R}^{\mathbf{2}}$ & $\mathbf{R}^{\mathbf{2}}$ & Slope $\mathbf{( n )}$ & $\mathbf{R}^{\mathbf{2}}$ \\
\hline F1 & 0.946 & 0.983 & 0.983 & 0.535 & 0.921 \\
F2 & 0.964 & 0.968 & 0.994 & 0.584 & 0.932 \\
F3 & 0.965 & 0.976 & 0.985 & 0.642 & 0.936 \\
F4 & 0.953 & 0.962 & 0.993 & 0.673 & 0.941 \\
F5 & 0.964 & 0.969 & 0.989 & 0.689 & 0.917 \\
F6 & 0.949 & 0.978 & 0.993 & 0.757 & 0.908 \\
F7 & 0.987 & 0.993 & 0.998 & 0.761 & 0.975 \\
F8 & 0.971 & 0.981 & 0.991 & 0.784 & 0.912 \\
F9 & 0.984 & 0.989 & 0.989 & 0.796 & 0.908 \\
\hline
\end{tabular}

Zero order equation, $C=K_{0} t$, First order equation, $\log C=\log C-K_{t} / 2.303$., Higuchi's equation, $Q=K t^{1 / 2}, K$ Korsmeyer et al's equation, $M_{t} / M_{\alpha}=K t^{n}$.

Swelling and Erosion Study: Swelling and erosion studies were carried out according to the method reported by Al-Taani and Tashtoush (2003), to understand the influence of swelling and erosion behaviour on drug release and also to determine the effect of polymer viscosity on the swelling and erosion. Matrix tablets were introduced into the dissolution apparatus under the standard set of 
conditions as specified for release rate studies. The tablets were removed using a small basket and swollen weight of each tablet was determined. To determine matrix erosion, swollen tablets were dried in a vacuum oven at $45^{\circ} \mathrm{C}$ to a constant weight. Swelling (\%) and Erosion (\%) were calculated according to the following formula: \% Swelling $=S / R \times 100, \%$ Erosion $=(T-R) / T \times 100 ;$ Where, $S$ is the weight of the matrix after swelling; $R$ is the weight of the eroded matrix; and $T$ is the initial weight of the matrix ${ }^{25}$.

Stability Studies: The optimized formulation was subjected to stability at $40 \pm 2{ }^{\circ} \mathrm{C}$ and $75 \pm 5 \%$ RH for period of six months. After each month tablet sample was analyzed for physical characteristics and drug release profile ${ }^{26}$.

RESULTS \& DISCUSSION: Granulation is the key process in the production of many dosage forms. To ensure good content uniformity and avoid flow related inter tablet weight variation problems, wet granulation is preferred in routine commercial production. Wet granulation was thus used in the present study. Physical properties of granules such as specific surface area, shape, hardness, surface characteristics and size can significantly affect the rate of dissolution of drug contained in a formulation.

Granules of the different formulations were evaluated for angle of repose, loose bulk density, tapped bulk density, and compressibility index. The results of angle of repose and compressibility index (\%) ranged from $\left(25.24^{0} \pm 1.25\right.$ to $\left.29.49^{\circ} \pm 1.28\right)$ and $(12.53 \pm 0.25$ to $16.72 \pm 1.38)$, respectively. The results of loose bulk density and tapped bulk density ranged from $(0.3454 \pm 0.05$ to $0.4150 \pm 0.04)$ and $(0.3979 \pm 0.004$ to $0.5054 \pm 0.008)$, respectively. The results of angle of repose $(<30)$ indicate good flow properties of granules. This was further supported by lower compressibility index values. The lowest compressibility index is $5-15 \%$ which indicates excellent flow properties in Table 2. The physical properties of different batches of developed matrix tablets are given in Table3. The thickness of the tablets ranged from $(3.75 \pm 0.04$ to $3.92 \pm 0.07) \mathrm{mm}$. All the batches showed uniform thickness. The average percentage deviation of 20 tablets of each formulation was less than (5\%), and hence all formulations passed the test for uniformity of weight as per official requirements (Pharmacopoeia of India 1996). The hardness of all the formulation ranged from $(6.2 \pm 0.12$ to $6.8 \pm 0.14)$ $\mathrm{kg} / \mathrm{cm}^{2}$.

Tablets hardness is, however, not an absolute indicator of strength. The percentage friability of the tablets of all the formulations ranged from $(0.29 \%$ to $0.42 \%)$. In the present study, the percentage friability for all for formulations was below $1 \% \mathrm{w} / \mathrm{w}$, indicating that the friability is within the prescribed limits. Drug content was found to be uniform among different formulations of the tablets and ranged from $(97.82 \pm 0.41$ to $99.12 \pm 0.18)$. The results of the dissolution studies for formulations F1 to F6 are shown in the Figure1.

The cumulative percentage drug release for F1, F2, F3, F4, F5 and F6 (98.45\%, 94.17\%, 81.45\%, $75.38 \%, 69.62 \%)$ at the end of 12 hrs respectively. Among all the formulation F1 shows highest drug release (98.45\%) in 10hrs, where as the drug release from other formulations was slow. It was found that the cumulative percentage of drug release decreases with increase in the polymer concentration.

The regression coefficients obtained for first order kinetics were found to be higher $\left(R^{2}: 0.962\right.$ to $0.993)$ when compared with those of zero order kinetics ( $R^{2}$ : 0.946 to 0.987 ), indicating that drug released from all formulation is first order kinetics (Table 4). To evaluate drug release mechanism from the matrix tablets, plots of cumulative 
percentage release vs square root of time as per Higuchi's equation were constructed. These plots were found to be linear with all the formulations $\left(R^{2}: 0.983\right.$ to 0.998$)$ indicating that the drug release from the matrix tablets was diffusion controlled. To confirm the diffusion mechanism the data were fit into korsmeyer et al's equation. All the formulation shows good linearity $\left(R^{2}: 0.908\right.$ to 0.975$)$, with the slope $(n)$ values 0.535 to 0.796 , indicating release mechanism was anomalous non-Fickian or anomalous release $(0.45<n<0.89)$. But it cannot be concluded that release was totally based on diffusion, which generally in the case in Higuchi's square root equation.

Based on swelling and erosion studies, it was concluded that matrix tablets undergo swelling as well as erosion during the dissolution study, which indicates that polymer relaxation had a role in drug release mechanism. However, it can be concluded that effect of release kinetics was found to be diffusion coupled with erosion.

CONCLUSION: From the above observations it is concluded that slow and controlled release of Lamivudine over a period of 12 hours was obtained from matrix tablets (F2 to F6). Use of natural hydrophilic polymer like guar gum was successful in the formation of matrix and at the same time it is effective in retarding the drug release. Among all the formulation, F2 shows that $94.17 \%$ of drug release at the end of 12 hours. The cumulative percentage drug was decreased by increase in polymer concentration. The mechanism of drug was diffusion coupled with erosion. The stability studies show that there was no significant change in hardness, friability, and drug content of selected formulation F2. The controlled and efficient drug delivery system developed in the present study will maintain plasma Lamivudine levels better, which will overcome the drawbacks associated with the conventional therapy.

\section{REFERENCES:}

1. Joint United Nations Programme on HIV/AIDS (UNAIDS) and World Health Organization (WHO). AIDS Epidemic Update2005. Geneva, Switzerland: UNAIDS. Available at: http://www.unaids.org/epi/2005/

doc/EPlupdate2005_pdf_en/epi-update 2005_en.pdf. Accessed. December 10, 2006.

2. Zhou J, Paton NI, Ditangco R: Experience with the use of a first-line regimen of Stavudine, lamivudine and nevirapine in patients in the TREAT Asia HIV Observational Database. HIV Medicine 2007; 8:8-16.

3. Castillo SA, Hernandez JE, Brothers $\mathrm{CH}$ : Long-term safety and tolerability of the lamivudine/abacavir combination as components of highly active antiretroviral therapy. Drug Safety 2006; 29 (8):11-826.

4. Hardman JG, Limbird LE, Molinoff PB, Ruddeon RW, Gilman AG; Goodman \& Gilman's the Pharmacological Basis of Therapeutics. McGraw-Hill, New York, 2001.

5. Sweetman SC, Martindale: In; the complete reference. Pharmaceutical Press Edition 33, 2002.

6. Welling PG, Dobrinska MR: Sustained and controlled release drug delivery systems, Marcel Dekker Inc, New York, 1978.

7. Karlos NN, Ostin PC: In-vitro-studies of diclofenac sodium controlled release from biopolymeric hydrophilic matrices. Journal of Pharmaceutical science 2003; 5(3): 213-219.

8. Rezal MD, Qadir MA, Haider S.S: Comparative evaluation of polymers as matrix for controlled release drug delivery. Journal of Pharmacy and Pharmaceutical Sciences. 2003; 6(2): 274-291.

9. Khullar P, Khar RK, Agarwal SP: Evaluation of guar gum in the preparation of sustained- release matrix tablets. Drug Development and Industrial Pharmacy 1998; 24:10951109.

10. Wassel GM, Omar SM, Ammar NM: Application of guar flour and prepared guaran in tablet manufacture. Journal of Drug Research 1989; 18:1-8.

11. Baweja JM, Mishra AN: Modified guar gum as a tablet disintegrant. Pharmazie 1997; 52:856-859.

12. Khullar P, Khar RK, Agarwal SP: Guar gum as a hydrophilic matrix for preparation of theophylline controlled-release dosage form. Indian Journal of Pharmaceutical Science 1999; 61:342-345.

13. Mishra AN, Baweja JM: Modified guar gum as hydrophilic matrix for controlled release tablets. Indian Drugs 1997; 34:216-223.

14. Bonferoni MC, Caramella C, Sangalli ME, Conte U, Pedraz $\mathrm{JL}$ : Rheological behaviour of hydrophilic polymers and drug release from erodible matrices. Journal of controlled Release. 1992; 18:205-212.

15. H. Kurahashi, H. Kami, H. Sunada. Influence of physicochemical properties on drug release rate from hydroxypropyl methylcellulose matrix tablets. Chem Pharm Bull (Tokyo). 1996, 44,829-832. 
16. Cooper J, Gunn G: Powder flow and compaction, In; Tutorial pharmacy, CBS Publishers and distributers, 1986.

17. Shah $Y$, Rampadhan $M$ : Development and evaluation of controlled release diltiazem hydrochloride microparticles using cross-linked polymer (vinayl alcohol). Drug Development and Industrial Pharmacy 1997; 23(6):567574.

18. Aulton ME, Well TI: Pharmaceutics: The Sciences of Dosage form Design, Churchill Livingstone, London, England, 1998.

19. Chang R, Robinson JR: Sustained release from tablets and particles through coating. In Pharmaceuticals dosage form tablets, Marcel Dekker, vol. III, 1990.

20. Hadjiioannou TP, Christian GD, Koupparis MA: Quantitative calculations in pharmaceutical practices and Research, VCH publishers Inc, New Delhi, 1993.

21. Bourne DW: Pharmacokinetics. In: Banker GS, Rhodes CT, eds. Modern Pharmaceutical. Marcel Dekker, Edition 4, 2002.
22. Higuchi T: Mechanism of sustained action medication. Theoretical analysis of rate of release of solid drugs dispersed in solid matrices. Journal of Pharmaceutical Science. 1963; 52: 1145-1149.

23. Koesmeyer RW, Gurny R, Doelker E, Buri P, Peppas NA: Mechanism of solute release from porous hydrophilic polymers. International journal of pharmaceutics 1983; 15:25-35.

24. Siepmann J, Peppas NA: Modelling of drug release from delivery system based on Hydroxypropylmethylcellulose (HPMC). Advanced Drug Delivery Review 2001; 48: 139157.

25. Al-Taani BM, Tashtoush BM: Effect of microenvironment $\mathrm{pH}$ of swellable and erodible buffered matrices on the release characteristics of diclofenac sodium. AAPS Pharm Science Technology. 2003; 4: E 43.

26. Cartensen JT: Drug Stability: Principle and Practices. Marcel Dekker, New Work, Edition 2, 1995. 